\title{
LOS HITOS PATRIMONIALES EN DIMENSIÓN TU- RÍSTICA. CASTILLA Y LEÓN Y LA REAL COLEGIATA DE SAN ISIDORO
}

\author{
María GARCÍA HERNÁNDEZ - Manuel DE LA CALLE VAQUERO \\ Grupo de Investigación Turismo, Patrimonio y Desarrollo. Universidad \\ Complutense de Madrid
}

\author{
Recibido: 31/10/2011 \\ Devuelto: $28 / 06 / 2012$ \\ Aceptado: 11/07/2012
}

RESUMEN: El patrimonio histórico constituye uno de los soportes sobre los que se apoya el desarrollo reciente del turismo de interior. Dentro de este patrimonio la afluencia turística se concentra sobre una serie limitada de hitos patrimoniales que responden a diferentes tipologías. En Castilla y León adquieren especial dimensión turística los conjuntos catedralicios, los castillos y fortalezas, conventos, abadías y monasterios, los museos que ocupan edificios históricos y los sitios arqueológicos. En estos lugares se plantea una problemática turística específica asociada al crecimiento de los flujos de visitantes: compatibilidad de usos, superación de umbrales de capacidad de carga, impactos sobre el patrimonio y el entorno inmediato, etc. La Real Colegiata de San Isidoro de León reúne las características que permiten su consideración como uno de los grandes hitos patrimoniales de Castilla y León. Ejemplifica bien la complejidad que encierra la gestión turística de los hitos en los que se desarrollan funciones de distinto tipo. Y también sirve como exponente de la preocupación que tienen los gestores por los aspectos relacionados con la organización de la visita pública y con otros componentes de la dimensión turística de los grandes espacios patrimoniales.

PALABRAS CLAVE: Patrimonio Histórico, Turismo, Cultural, Castilla y León, Real Colegiata de San Isidoro de León, Capacidad de Carga Turística.

\footnotetext{
${ }^{1}$ Este texto se enmarca dentro del proyecto "La capacidad de carga como instrumento de planificación y gestión de los recursos turístico-culturales". Ministerio de Ciencia e Innovación. Plan Nacional de I+D+i (2008-2011). Referencia: CSO2010-20702 GEOG. Dpto. de Geografía Humana (UCM). Años 2011-2013. Investigadora principal: María García Hernández. En cuanto a la información de base de San Isidoro de León, se ha elaborado en el marco del proyecto "La Colegiata de San Isidoro de León. Estudio del funcionamiento turístico y cultural del Conjunto" realizado por encargo de la Fundación Caja Madrid bajo dirección de Miguel Ángel Troitiño Vinuesa y con participación de los autores como equipo redactor.
} 
HERITAGE LANDMARKS IN THEIR TOURISTIC DIMENSION. CASTILLA Y LEÓN AND THE ROYAL COLLEGIATE OF SAN ISIDORO

ABSTRACT: Cultural heritage is very important for tourist development in Spain. Nevertheless, the tourist flows are concentrated on a limited set of monuments: cathedral, castles and fortresses, monasteries, abbeys, museums holding historic buildings and archaeological sites. These sites pose a specific tourism issues associated with growth of visitor flows: compatibility of uses, risk of congestion, impacts on heritage and environment, etc. The Collegiate Church of San Isidoro de Leon is one of the most important tourist monuments in Castilla and Leon. It exemplifies the complexities of the tourism management at multifunctional heritage buildings.

KEY WORDS: Heritage, Cultural Tourism, Castilla y León, Real Colegiata de San Isidoro de León, Tourist Carrying Capacity.

\section{INTRODUCCIÓN}

Desde los primeros trabajos la investigación española en Geografía del Turismo se ha centrado sobre dos grandes ámbitos de reflexión: los recursos y los destinos turísticos. El concepto de recurso lleva implícito las nociones de valor, de interés, de algo que satisface las necesidades o deseos de alguien (LENO CERRO, 1993). En relación a la cultura, cabe señalar que los "recursos culturales" están conformados por aquellos elementos o manifestaciones de la cultura que presentan valor o interés para la comunidad local. En otros términos, satisfacen alguna de sus necesidades y, por lo tanto, soportan buena parte de los consumos culturales de la población residente. De forma paralela, una parte de estos recursos constituye la base sobre la que se construye el turismo cultural, el conjunto de consumos culturales realizados por turistas y excursionistas. Sin embargo la mirada turística es aún más selectiva, no atiende a la totalidad de los recursos existentes en los lugares que visita sino que centra su interés en un número reducido de manifestaciones de la cultura local. En principio, cabe considerar este subconjunto de recursos culturales con dimensión turística -en función de su interés para los visitantes foráneos- como "atractivos o recursos turístico-culturales".

El patrimonio histórico, que hace referencia a la memoria de los lugares, constituye uno de los componentes de la cultura local. Como sucede con el resto de las manifestaciones de la cultura (creaciones y expresiones artísticas, industrias culturales, etc.), sólo una parte del entramado patrimonial deviene en un recurso turístico efectivo. Este artículo se centra específicamente sobre los grandes "hitos patrimoniales", condición que se otorga a los elementos del patrimonio inmueble que cumplen las siguientes características: 1. Se trata de conjuntos edificados con elevado valor arquitectónico - de ahí su consideración como Bienes de Interés Cultural- y que en muchas ocasiones albergan también notables colecciones de patrimonio mueble. 2. En líneas generales presentan grandes dimensiones, lo que implica un tratamiento 
donde se incorporan dimensiones arquitectónicas y urbanísticas. 3. Son grandes referentes turísticos de los lugares donde se sitúan, hitos de gran afluencia turística que tienden a convertirse en los iconos de los destinos. 4. Dentro de su programa de usos cobra especial importancia la organización de la visita pública, aunque no necesariamente implique el reconocimiento del turismo como función central del espacio. 5. Y existe una gestión unitaria de dicho espacio, con una serie de agentes responsables claramente identificables que cuentan con un programa funcional que sirve de base para la gestión del sitio.

Dentro del ámbito castellano hablante existe tendencia a utilizar el término "recurso turístico" con cierta ambigüedad. En un sentido amplio, incluye todos los elementos que potencialmente resultan atractivos para un visitante genérico. Esta acepción está en la base de los inventarios que evalúan el potencial turístico de un territorio (LÓPEZ OLIVARES, 1998 y 2005; CEBRIÁN ABELLÁn et AL., 2010) y de los atlas turísticos (INSTITUTO GEOGRÁFICO NACIONAL, 2004 y $2008^{2}$ ). En otras ocasiones se restringe el concepto a aquellos elementos o manifestaciones que ya forman parte del mercado turístico, que de hecho funcionan como productos turísticos. En los trabajos en inglés, y referidos específicamente al turismo y la cultura, se asocia "resources" con los elementos del patrimonio territorial de potencial turístico (JANSEN-VERBEKE et AL., 2008) y "attractions" para aquellos bienes y manifestaciones acondicionados para un uso turístico efectivo y con un programa de comunicación explícito (RICHARDS, 2001 y 2002; LEW, 2002). A efectos de este artículo, el patrimonio histórico forma parte de los recursos territoriales turísticos de un lugar. Se sitúa por lo tanto en el nivel de la potencialidad. En cambio, los hitos patrimoniales se integran dentro de las atracciones turísticas activas de un destino. En otros términos, ya están situadas en el mercado aunque con desigual fortuna.

Estas reflexiones se enmarcan en un proyecto más general de investigación centrado sobre la capacidad de carga de los grandes recursos turísticoculturales (GARCÍA HERNÁNDEZ et AL., 2011). De forma específica, en los epígrafes siguientes se aborda una lectura de los grandes hitos patrimoniales de Castilla y León en dimensión turística. En la primera parte se realiza una panorámica general del objeto de investigación. Además de los inventarios regionales de bienes culturales, se ha recurrido al uso de los datos de distin-

\footnotetext{
${ }^{2}$ En las Monografias..., los apartados correspondientes al patrimonio histórico fueron elaborados por Manuel de la Calle y María García de la Universidad Complutense. Dentro de la sección dedicada a las Comunidades Autónomas, la autoría del apartado de Castilla y León corresponde a Ignacio Plaza y Luis Alfonso Hortelano de la Universidad de Salamanca.
} 
tos observatorios turísticos (Ávila, León, Palencia, Segovia, Salamanca Grupo de Ciudades Patrimonio de la Humanidad de España, etc.) y a la información proporcionada por distintas instituciones (Patrimonio Nacional, Museos de Castilla y León, etc.). En la segunda parte se profundiza sobre la situación específica de la Real Colegiata de San Isidoro de León, uno de los grandes hitos patrimoniales de la región. Espacio necesitado de una profunda renovación, ejemplifica las posibilidades y contradicciones del uso turístico de los grandes referentes patrimoniales. Dentro del apartado de conclusiones, para finalizar se señalan una serie de consideraciones finales que sirven como guía futura de investigación.

\section{EL PATRIMONIO MONUMENTAL DE CASTILLA Y LEÓN EN DIMENSIÓN TURÍSTICA.}

Como es de sobra conocido, Castilla y León acoge en su territorio un legado de manifestaciones patrimoniales de impresionante magnitud y heterogeneidad, legado que actúa como factor de desarrollo turístico. Aún limitándose a los bienes inmuebles de mayor relevancia, la base documental de la Consejería de Cultura y Turismo (2011) recoge información sobre un total de 1.895 elementos que ostentan la condición de Bienes de Interés Cultural (B.I.C.). La mayor parte de estos Bienes (1.243) corresponden a alguna de las categorías establecidas en la Ley 12/2002, de 11 de julio, de Patrimonio Cultural de Castilla y León: Conjunto Etnológico (4), Conjunto Histórico (140), Jardín Histórico (2), Monumento (980), Sitio Histórico (8) y Zona Arqueológica (109), además de Vía Histórica (0). El resto se adscriben a categorías antiguas (6 Parajes Pintorescos), bienes sin adscripción (48) y declaraciones genéricas (598 elementos) que afectan a distintas tipologías patrimoniales. Entre estas destacan los castillos (Decreto de 22 de abril de 1949, referido a los Castillos de España) y las cuevas, abrigos y lugares que contienen manifestaciones de arte rupestre (Ley 16/1985, de 25 de junio, del Patrimonio Histórico Español). Dentro de este conjunto tan amplio la UNESCO reconoce un valor especial a los ocho bienes inscritos en la Lista del Patrimonio Mundial: la Catedral de Burgos (incorporada a la Lista en 1984), la Ciudad antigua de Segovia y su Acueducto Romano (1985), la Ciudad antigua de Ávila y sus Iglesias de Extramuros (1985), la Ciudad antigua de Salamanca (1988), el Camino de Santiago (1993), Las Médulas (1997), el Sitio arqueológico de Atapuerca (2000) y los Yacimientos de Arte Rupestre Prehistórico de Siega Verde (2010).

\section{II.1. Grandes tipologías turísticas del patrimonio de la región.}

Los grandes hitos patrimoniales a los que hace referencia este artículo ostentan en su mayoría la condición de Monumentos o Zonas Arqueológicas, 
aunque también se referencian otras categorías dependiendo del momento en que se incoó su expediente de declaración. Bajo un criterio funcional es posible diferenciar los bienes en donde prima la función cultural -en la mayoría de las ocasiones espacios sujetos a musealización- de aquellos hitos donde la visita pública está supeditada a otras funciones de mayor prevalencia, caso de los bienes dependientes de la Iglesia y Patrimonio Nacional. Según los modelos de gestión adoptados encontramos diferencias significativas de acuerdo a los planteamientos, objetivos y modelos organizativos de las entidades que gestionan estos hitos: el conglomerado de organizaciones que forman la Iglesia Católica, la administración cultural en el nivel estatal, autonómico y local, Patrimonio Nacional, fundaciones, universidades... e incluso otros organismos estatales como el Ministerio de Defensa, responsable del Alcázar de Segovia. De forma complementaria, bajo un criterio de impronta territorial es posible diferenciar entre los hitos aislados donde tiende a confundirse los límites entre recurso y destino turístico de escala local, de aquellos referentes que forman parte de destinos turísticos más complejos, caso de ciudades o comarcas con una mayor dotación de atractivos turísticos. Combinando estos y otros criterios, dentro de Castilla y León es posible establecer una tipología en la que tienen cabida cinco grandes grupos de elementos patrimoniales: 1. Catedrales y otros grandes lugares de culto; 2. Abadías, monasterios y conventos; 3. Castillos y otros elementos defensivos; 4. Museos en edificios históricos; y 5. Zonas arqueológicas. Además cabe considerar manifestaciones complementarias, caso de los palacios (San Ildefonso de La Granja, Riofrío...) y edificios universitarios (Salamanca...), con menor presencia en Castilla y León que en otras comunidades autónomas.

Los conjuntos catedralicios constituyen los principales referentes patrimoniales y turísticos de las capitales diocesanas de la región: Astorga, Burgo de Osma, Ciudad Rodrigo y la totalidad de capitales de provincia. En tanto que bienes pertenecientes a la Iglesia Católica, la prevalencia corresponde a la función religiosa en sus diferentes componentes. No obstante, la dimensión turística de las catedrales es un hecho innegable y desde hace décadas han tenido que ir adaptándose a un uso turístico cada vez más masivo. Los cabildos catedralicios han respondido a esta afluencia creciente de visitantes -con una orientación hacia la religión muy diversa- mediante distintas fórmulas. De una parte se ha procedido a organizar la visita dentro del templo principal e instalaciones anexas. Aquí nos encontramos con situaciones muy variadas, desde lugares donde las naves principales pueden recorrerse libremente y de forma gratuita (caso de Santa María de León hasta fechas recientes) hasta catedrales donde la visita se realiza mayoritariamente mediante pago (El Salvador de Ávila). Sistemas intermedios se registran en Salamanca (Catedral Nueva de entrada gratuita y Catedral Vieja de pago) y Santa María de Astor- 
ga (visita libre durante determinadas horas, visita de pago vinculada a la entrada al Museo el resto del tiempo). En paralelo se han ido configurando museos catedralicios y diocesanos, con diferentes niveles de adecuación museográfica. Y más recientemente se han incorporado fórmulas complementarias de visita que implican una renovación notable del producto turístico ofertado. Es el caso de la propuesta asociada a "Ieronimus" en Salamanca y el programa de visitas organizadas en el marco del Proyecto Cultural de la Catedral de León "El Sueño de la Luz".

El segundo gran componente del patrimonio de la Iglesia está formado por el conjunto de abadías, monasterios y conventos, bienes dependientes de diferentes órdenes del clero regular y dos de ellos cuya visita depende de $\mathrm{Pa}$ trimonio Nacional por estar bajo el amparo de la Corona (Real Monasterio de Santa Clara de Tordesillas y Monasterio de Santa María la Real de las Huelgas en Burgos). A diferencia de las catedrales, estrechamente asociadas al ámbito urbano, el patrimonio conventual y monástico se encuentra mucho más disperso por el territorio de la región, actuando como referente de visita de distintos tipos de destinos turísticos. A nivel urbano, los conventos de Santo Tomás, San José o Las Madres y Santa Teresa constituyen tres de los principales referentes turísticos de la ciudad de Ávila. De mayor relevancia para los municipios donde se sitúan son los monasterios de Santo Domingo de Silos y Santa Clara de Tordesillas, que actúan como nodos de atracción en el marco de desplazamientos de un turismo de base rural y/o cultural asociado a las comarcas de interior. Además de la visita general, su trascendencia turística deriva de la creciente oferta de productos gastronómicos y de la prestación de servicios singulares de alojamiento (hospedería monástica de Santa María de Huerta, el ya citado Santo Domingo de Silos o la Casa de Espiritualidad de la Colegiata de san Isidoro).

También los castillos y otros elementos de arquitectura defensiva presentan una elevada dispersión sobre el territorio regional, con notables manifestaciones a nivel urbano (Murallas de Ávila, Castillo de Zamora, etc.) y otro conjunto muy amplio de estructuras repartidas en comarcas de mayor ruralidad (castillos de Coca, Montemayor del Río y un largo etcétera). La responsabilidad de la gestión de estos recintos varía considerablemente. En un número reducido de casos dependen directamente de la administración regional (Castillo de la Mota) y de las diputaciones provinciales (Castillo de Peñafiel). En otras ocasiones son de titularidad y gestión privadas, como sucede con el Castillo de Ampudia de la Fundación Eugenio Fontaneda. En general después de un largo periplo, también muchos ayuntamientos han acabado asumiendo la responsabilidad sobre algunos de los recintos fortificados que existen en sus municipios. Así ha sucedido en La Adrada, Cuéllar y Ponfe- 
rrada. Con independencia del agente responsable de su gestión, cabe señalar que durante los últimos años este componente del patrimonio castellanoleonés ha recibido una atención preferente en términos turísticos. Además de establecer el programa general de visitas, en algunos recintos hace tiempo se llevan ensayando las visitas guiadas en grupo, visitas teatralizadas y sistemas de entrada combinada con otros referentes patrimoniales del destino. Incluso se han creado centros de interpretación a efectos de reforzar el atractivo turístico del castillo.

El cuarto gran componente del patrimonio de la comunidad autónoma se corresponde con los museos que ocupan edificios históricos. Dado que la práctica totalidad de estos museos conservan colecciones relacionadas con el legado histórico de la región, el valor patrimonial es doble: de una parte, el valor de la colección de bienes muebles (cuadros, esculturas, documentos, piezas arqueológicas, etc.); de otra, el valor arquitectónico del edifico en sí, que a su vez ostenta la condición de BIC. El ejemplo más representativo de esta conjunción de valores es el conjunto de museos provinciales, cuyos primeros contenidos derivan de las desamortizaciones del siglo XIX. El Museo de Ávila se sitúa en la Casa de los Deanes y cuenta con un anexo visitable en la Iglesia de Santo Tomé el Viejo. En Burgos, el museo provincial ocupa la Casa Miranda y el Palacio Angulo. Las instalaciones originales del Museo de León estaban en dependencias del antiguo convento de San Marcos; en la actualidad sigue ocupando parte, que se gestiona como "anexo monumental". El Museo de Palencia ocupa la Casa del Cordón, el de Salamanca la Casa de los Abarca, el de Segovia la Casa del Sol y el de Valladolid el Palacio de Fabio Nelli. Además los restos del monasterio de San Juan del Duero acogen la sección medieval del Museo Numantino de Soria y la Iglesia de San Juan de los Caballeros es la sede del Museo Zuloaga, filial del Museo de Segovia. Aunque de titularidad estatal, la gestión corresponde a la comunidad autónoma desde 1986. No obstante, el Ministerio de Cultura sigue gestionando de forma directa la Casa-Museo de Cervantes y el Colegio de San Gregorio-Museo Nacional de Escultura, ambos situados en la ciudad de Valladolid.

Las zonas arqueológicas constituyen una tipología de notable peculiaridad dentro de los hitos patrimoniales. A nivel general, los grandes conjuntos arqueológicos devienen en recursos turísticos de primer orden desde los inicios del turismo moderno. La evocación de las "ruinas" -heredera de la visión romántica del patrimonio- atrae todavía multitud de visitantes. Es más, la puesta en marcha durante los últimos años de proyectos de investigación y valorización del patrimonio arqueológico y paleontológico -que ha ganado en accesibilidad- ha incrementado notablemente la proyección social, educa- 
tiva, cultural y turística de este tipo de patrimonio. Y todo ello a pesar de las dificultades para transformar este conjunto de recursos culturales en productos de consumo para el mercado turístico: escasa "entidad monumental" de la mayor parte de los restos excavados, ubicación aislada en el medio rural que entraña dificultades de accesibilidad e integración dentro del esquema básico de visita, reducida legibilidad de buena parte de este patrimonio, etc. De forma específica, la situación en Castilla y León se caracteriza por la pluralidad de fórmulas de gestión y presentación de yacimientos y zonas arqueológicas, lo que dificulta la visualización de la arqueología como un componente central y unitario del producto turístico regional. Dentro de este producto, destaca la creciente proyección turística de Atapuerca, que se presenta al visitante como un "sistema" formado los yacimientos de la Sierra, los centros de recepción de visitantes de Atapuerca e Ibeas de Juarros, el parque arqueológico de Atapuerca y el recientemente inaugurado Museo de la Evolución Humana de Burgos. En un segundo nivel se encuentran yacimientos y zonas de larga trayectoria turística -caso de Numancia y Tiermes en Soria y La Olmeda en Palencia- así como espacios cuya activación turística ha ido asociada a su inclusión en la Lista del Patrimonio Mundial, como sucede con Las Médulas y mucho más recientemente Siega Verde. En última instancia encontramos un sinfín de zonas de visita libre, si acaso con un somero acondicionamiento del sitio (Raso de Candeleda, Ulaca...) y a veces dotadas con aulas arqueológicas (Mesa de Miranda, Las Cavenes, Fuenteungrillo...). Estas aulas, que funcionan como centros de interpretación, suelen ser de gestión municipal o comarcal y en muchos casos han sido financiadas por la Fundación del Patrimonio Histórico de Castilla y León.

En este esquema tipológico encajan los hitos de mayor proyección turística de la región. Resulta además operativo a efectos de trabajar problemas de gestión ya que el funcionamiento de cada uno de los elementos que se engloban en los diferentes tipos responde en grandes rasgos a lógicas más o menos constantes que derivan de los agentes que detentan la propiedad y de los modelos de gestión adoptados. No obstante, siempre es aventurado realizar tipologías pues la realidad suele tener una riqueza de matices que resiste el encasillamiento en compartimentos estancos. Además se corre el riesgo de dejar fuera manifestaciones de interés, por mucho que en la actualidad su recorrido turístico sea limitado. Es el caso del patrimonio industrial, las nuevas arquitecturas, etc.

\section{II.2. Afluencia de visitantes y problemática turística.}

Como se ha señalado anteriormente, la totalidad de los hitos patrimoniales a los que se ha hecho referencia inciden de forma notable sobre la estructura y dinámica turística de los destinos de los que forman parte, ya sean ciuda- 
des o comarcas rurales. No en vano alguno de estos referentes reciben cada año varias decenas de miles de visitantes. Como sucede en otros lugares, las catedrales constituyen grandes iconos turísticos de Castilla y León, hitos que forman parte fundamental de la imagen turística de las ciudades donde se sitúan y nodos básicos de la visita. La Catedral de Burgos oscila entre 280.000 y 300.000 visitantes anuales, la de Segovia registró 206.835 visitas en 2009 y la de Ávila 129.112 en 2010. La primacía de la visita libre en otros conjuntos catedralicios se traduce en ausencia de registros de visitas o si acaso en registros muy parciales. En Salamanca, "Ieronimus" sumó 124.994 visitas en 2010; en León, el Museo Catedralicio-Diocesano alcanzó 30.298 también en 2010 y el conjunto de visitas asociadas al proyecto "El Sueño de la Luz" ronda las 42.000 personas anuales. Además de las catedrales, existe a nivel urbano todo un conjunto complementario de referentes patrimoniales que superan las 100.000 visitas anuales, caso del Alcázar de Segovia (478.006 visitantes en 2009), las Murallas de Ávila (169.467 en 2010), el Edificio Histórico de la Universidad de Salamanca (147.244 en 2008) y el Museo Nacional Colegio de San Gregorio en Valladolid (136.560 en 2010). En líneas generales, los hitos situados en zonas rurales registran una afluencia menor de visitantes. Así la villa romana de La Olmeda, dependiente de la Diputación Provincial de Palencia, registró 84.735 visitas en 2010. En Soria, San Baudelio de Berlanga alcanzó 74.671 en 2009, Numancia 62.933 y Tiermes 18.967. En Valladolid, el Monasterio de Santa Clara de Tordesillas llegó a 36.870 visitas también en 2009. Y en Segovia, la proximidad al área madrileña explica las elevadas cifras de visitantes: 251.726 en el Palacio Real de La Granja y 79.230 en Ríofrío.

A efectos de mejorar la comprensión del significado turístico de estas cifras, resulta conveniente situarlas en un marco interpretativo más amplio. La comparación con otros grandes hitos patrimoniales situados en España refleja que, en términos absolutos, no se trata de cifras muy elevadas. Durante 2010 se registraron 2.732.000 visitantes en el Museo del Prado de Madrid y 2.371.349 en la Sagrada Familia de Barcelona. Más significativa resulta aún la afluencia contabilizada en las grandes capitales andaluzas: 2.170.250 en la Alhambra y Generalife de Granada, 1.305 .000 en la Catedral de Sevilla y 1.169.233 en la Mezquita-Catedral de Córdoba. Los datos de afluencia de los dos primeros responden a su situación en áreas metropolitanas muy pobladas que son a su vez grandes destinos de turismo urbano a nivel europeo. Las ciudades andaluzas, que devienen en destinos turísticos desde los inicios del turismo moderno, responden más a un turismo cultural de perfil más tradicional, con fuerte presencia de visitantes extranjeros. 
Sin embargo, estas cifras de afluencia dan idea de la importancia que tienen los grandes iconos castellano-leoneses a nivel de cada destino turístico. Los 478.006 visitantes del Alcázar contrastan con los apenas 207.000 viajeros alojados en los hoteles de la ciudad, de acuerdo a los datos aportados por la Encuesta de Ocupación Hotelera del INE. Esta diferencia se debe sobre todo al peso del excursionismo, aspecto que también se aprecia en ciudades como Granada (1.451.016 turistas en alojamiento hotelero) y Córdoba (697.139). En el resto de las ciudades de la región la situación se invierte: 3,97 viajeros por cada visitante del Edificio Histórico de la Universidad de Salamanca, 2,48 por visitante del Museo Nacional Colegio de San Gregorio de Valladolid, 1,23 por visitante de la Catedral de Burgos y 1,20 por visitante que accede a la Muralla de Ávila. Estos valores derivan de dos factores cuyo peso varía en función de cada ciudad: de una parte, el peso del excursionismo, especialmente potente en las localidades cercanas a las principales áreas de emisión/remisión de visitantes; de otra, la estructura de atractivos turísticos de cada lugar, con localidades donde la visita se concentra sobre uno o dos referentes turísticos frente a otros sitios donde el interés de los visitantes se reparte entre un mayor número de atractivos turístico-culturales.

La dinámica de la visita a los grandes hitos patrimoniales muestra una evolución positiva, especialmente marcada desde principios de los noventa del siglo pasado. La práctica totalidad de los hitos situados en Castilla y León han experimentado importantes aumentos en el número de visitantes, paralelos al espectacular despegue que experimentó el conglomerado formado por los turismos de interior, cultura, ciudad, etc. En líneas generales este crecimiento se mantuvo hasta 2007, año a partir del que se viene experimentando una dinámica negativa asociada a la recesión económica general. Por ejemplo, la Catedral de Segovia pasa de contabilizar 221.298 visitas en 2007 a 206.835 en 2009, la Muralla de Ávila de 205.180 a 162.855 y la Colegiata de San Isidoro de León de 107.320 a 90.848 . Más allá de estas dinámicas de coyuntura resulta especialmente preocupante que la evolución de la afluencia registrada en estos y otros grandes referentes turísticos ha experimentado un comportamiento peor que la afluencia turística general medida en número de viajeros alojados en hoteles. En otros términos, en los momentos de crecimiento se ha incrementado más el número de turistas en destino que el número de visitas en los grandes hitos patrimoniales; y cuando llega la recesión, afecta con mayor intensidad a estos atractivos que al conjunto del destino. Y todo ello en un marco general caracterizado por cierto rezago de las ciudades medias de dominante patrimonial sobre las grandes metrópolis turísticas, uno de los componentes del turismo europeo que viene experimentado mejor comportamiento durante los últimos años. En este sentido cabe plantearse si nos acercamos a cierto estancamiento (¿agotamiento?) del mo- 
delo de turismo cultural de base patrimonial más clásico. Este estancamiento estaría afectando a destinos turísticos muy consolidados cuyo atractivo se basa en el patrimonio inmueble y, dentro de cada destino, a los referentes tradicionales de visita, ya sean monumentos o museos en edificios de interés histórico-artístico.

Con independencia de estas u otras previsiones, lo cierto es que las actuales cifras de visitantes ya plantean importantes desafíos de gestión patrimonial y están en la base de algunos de los problemas que genera la inserción de la función turística en el seno de los grandes hitos patrimoniales. Tanto o más relevante que el volumen global de visitantes es su reparto temporal, con medias diarias que rondan las 1.350 visitas por día en el Alcázar de Segovia y las 500 en la Muralla de Ávila. No obstante, la distribución temporal de la afluencia arroja muchas diferencias entre periodos. Como se observa en el gráfico de la distribución mensual de las visitas, existen tres temporadas turísticas que en buena medida responden a las condiciones de confort climático de la región: una temporada alta, asociada al verano y especialmente a agosto; una temporada media, que se reparte entre los meses más cálidos de la primavera y el otoño; y la temporada baja que corresponde básicamente a los meses más oscuros y/o fríos. No obstante, los picos máximos diarios (más de 2.800 personas registradas un día de 2006 en la Muralla de Ávila) suelen repartirse entre determinados momentos de la Semana Santa, el mes de agosto y pequeños periodos festivos de los meses de mayo, octubre e incluso diciembre.

Los problemas que derivan de la inserción de la función turística sobre los hitos patrimoniales son de diferente tipo y están estrechamente ligados a la magnitud de la afluencia de visita y a las constricciones o limitaciones que vienen dadas por las características del sitio, su modelo de gestión, las relaciones con el entorno y los recursos disponibles para adecuar espacios y prestar servicios a los visitantes. En relación con el entorno inmediato, el funcionamiento turístico del hito patrimonial tiende a producir cambios en el perfil funcional -con aparición de negocios vinculados al consumo de los visitantes-, en el tráfico -que se hace más denso-y el aparcamiento -más difícil-. A nivel interno, los mayores problemas derivan de la compatibilidad / incompatibilidad de usos (religiosos, institucionales... y turísticos). Estos problemas se agravan además cuando la afluencia turística empieza a crecer. En algunos de los principales referentes patrimoniales del país la elevada afluencia de visitantes -normalmente concentrada en el tiempo y en el espacio- plantea problemas específicos que tienen que ver con la saturación turística e implican la superación de los umbrales de capacidad de carga. En 
estos casos se suele hacer patente el deterioro de la calidad de la visita, un aspecto cualitativo difícil de explicitar y medir.

Gráfico 1. Distribución mensual visitas (2009, \%)

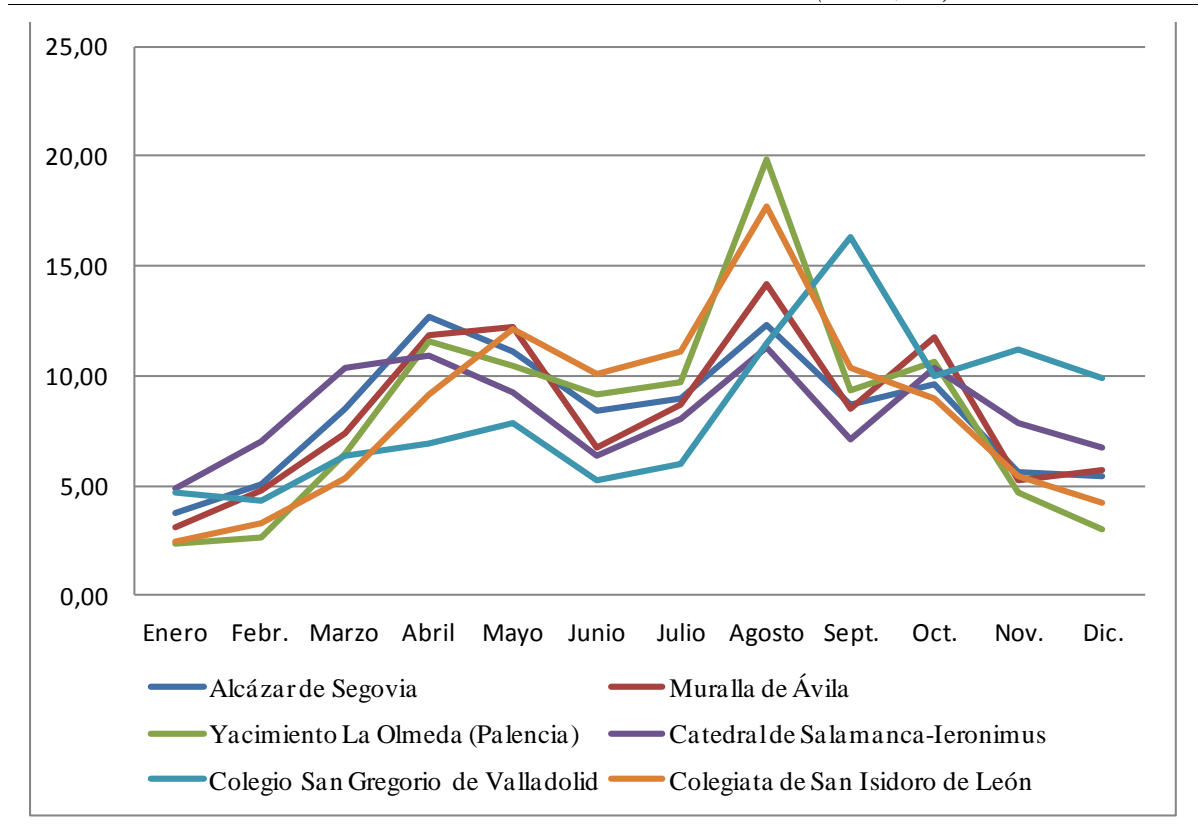

FUENTE: Proyecto "La capacidad de carga como instrumento de planificación y gestión de los recursos turístico-culturales".

En líneas generales, pues, una afluencia alta de visitantes dificulta la compatibilidad de usos y plantea retos adicionales en la gestión del entorno donde se sitúa el hito patrimonial -en buena medida relacionados con la accesibilidad externa a dicho hito-, pero también produce impactos sobre el medio físico (la fábrica de los edificios o el contenido mueble de algún contenedor arquitectónico) y genera un aumento del gasto asociado a las tareas básicas de conservación y mantenimiento del referente patrimonial. En ciertos casos los ingresos que genera la llegada de visitantes, llegado un punto de inflexión, no compensan los gastos ocasionados por el uso que hacen esos visitantes del espacio, desequilibrando la balanza de costes-beneficios. Por otra parte el aumento de la llegada de visitantes lleva así mismo aparejado un crecimiento de las necesidades asociadas a la prestación de servicios básicos para el desarrollo de la visita: tareas de control, vigilancia y seguridad, mantenimiento y limpieza y adecuación de espacios de recepción y organización de la visita. Finalmente los problemas de circulación y gestión de flujos se convierten en un tema clave para el funcionamiento diario de estos grandes 
hitos, con una preocupación clave: asegurar la seguridad del visitante (sistemas de evacuación ante situaciones de riesgo, previsión y seguros para accidentes de distinto tipo, etc.).

La falta de recursos económicos y/o humanos -generalmente equipos técnicos- no viene sino a agravar estos problemas. De hecho en algunos de los principales hitos turístico-patrimoniales, aunque se generan recursos suficientes para hacer frente a las tareas básicas de difusión del patrimonio (apertura pública, etc.), los objetivos de la gestión económica atienden a prioridades que poco o nada tienen que ver con la gestión de la visita y la atención al público. En otros casos, la escasez de personal para desempeñar las tareas relacionadas con la gestión turística del referente patrimonial hace que se perpetúen problemas que tendrían fácil solución de contar con equipos cualificados, especializados o simplemente dedicados a estas tareas concretas. Los gestores culturales son sensibles a esta problemática y existe una creciente preocupación por los temas relacionados con la correcta gestión turística de los elementos patrimoniales.

Con el aumento de la afluencia de visita a los referentes del patrimonio histórico se está generando una importante demanda de conocimiento en relación a temas como la organización de los flujos de visitantes, la adecuación del espacio utilizado para la visita, la ordenación de usos en los grandes conjuntos arquitectónicos o el estudio de la capacidad de carga turística. En este sentido diversos organismos internacionales han generado durante los últimos años cierta doctrina en relación a la gestión de la visita pública y la necesidad de controlar y/o regular el uso turístico de los recursos culturales en aras de garantizar su conservación, pero haciendo hincapié también en la necesidad de garantizar la calidad de la experiencia de visita (Carta del Turismo Cultural, ICOMOS, 1999). El Centro del Patrimonio Mundial de la UNESCO y la Organización Mundial del Turismo abordan de forma explícita estos aspectos en diferentes documentos: Handbook Tourism Congestion Management at Natural and Cultural Sites (WTO, 2005), Tourism at World Heritage Cultural Sites. The Site Manager's Handbook (WTO-ICOMOS, 1993). De hecho, paulatinamente estas preocupaciones acaban impregnando los documentos de ordenación y constituyen un elemento central de los Planes de Gestión que la UNESCO exige a los sitios incluidos en la Lista del Patrimonio Mundial. En el contexto castellano-leonés ya el Plan Director de Numancia de 1994 planteaba como objetivo central la integración de las actuaciones de investigación, conservación, difusión y gestión en el yacimiento (Jimeno MARTínEZ, 2000). Más recientemente, los Planes de Adecuación y Usos de los Espacios Culturales de Atapuerca y Las Médulas, ambos presentados en 2011, incluyen referencias directas a la organización de la visita pú- 
blica y sus infraestructuras (elaboración de planes de visita, directrices relativas a la señalización, accesibilidad y equipamientos para el visitante, etc.). Y esta preocupación aparece en el conjunto de operaciones de recuperación que se están llevando a cabo en la Colegiata de San Isidoro, uno de los principales hitos turístico-patrimoniales de la ciudad de León.

\section{LA REAL COLEGIATA DE SAN ISIDORO DE LEÓN: CLA- VES CULTURALES Y TURÍSTICAS.}

La Real Colegiata de San Isidoro de León constituye uno de los hitos patrimoniales más importantes de Castilla y León. Es uno de los conjuntos arquitectónicos más destacados por su historia, arquitectura, pintura, escultura, por los objetos suntuarios que conserva en su museo (Tesoro de León) y por el tesoro bibliográfico que alberga su biblioteca histórica (códices, manuscritos, incunables). Presenta además la particularidad de albergar el Panteón Real (o Panteón de los Reyes de León) ubicado a los pies de la Iglesia, con pintura mural románica y capiteles de gran valor. La parte fundamental del conjunto fue construido durante los siglos XI y XII, pero en él se imbrican piezas de distintas épocas: restos romanos de la Muralla adosados a su fachada oeste; construcciones románicas de la Iglesia con sus dos portadas, la Tribuna Real (ubicación del Tesoro), la Torre del Gallo y el pórtico del claustro procesional; aportaciones del gótico como la Capilla Mayor, el Retablo Mayor, el coro, y varias capillas del templo; importantes aportaciones del renacimiento como la Biblioteca y la Escalera Prioral; y finalmente también intervenciones del barroco en el Refectorio (Salón del Pendón) y los dos claustros del conjunto.

Como en otros grandes hitos patrimoniales de la región, durante los últimos años la Colegiata está siendo objeto de una importante labor de recuperación. Se ha intervenido en diferentes partes del conjunto (interior del Templo, Residencia de Canónigos, Casa de Espiritualidad...) y por parte de distintas entidades. Dentro de este proceso de recuperación emerge como una preocupación constante la dimensión turística de la Colegiata. En este marco, la Fundación Caja Madrid, responsable del proyecto de reforma del Museo, planteó la necesidad de elaborar un estudio sobre el funcionamiento turístico y cultural del conjunto, estudio encargado al Grupo de Investigación Turismo, Patrimonio y Desarrollo de la Universidad Complutense de Madrid. En este trabajo, que sirve de base para los epígrafes siguientes, se han abordado temas como el análisis del perfil de los visitantes, la capacidad de carga de los espacios acondicionados para la visita, el potencial competitivo de la Casa de Espiritualidad como establecimiento hotelero y la posición de la Colegiata en el contexto turístico de León. 


\section{III.1. Estructura organizativa y programa funcional.}

La Real Colegiata de San Isidoro es un recinto amplio (13.276 $\left.\mathrm{m}^{2}\right)$; se configura como un espacio de funcionamiento complejo que aglutina en la actualidad diferentes usos. En el conjunto de edificios dependientes del Cabildo Secular Diocesano, que rige hoy la institución, es posible identificar al menos seis grandes funciones: religiosa, museística, de custodia documental, de investigación-formación, de alojamiento permanente y turístico, y de difusión cultural. Cada función conlleva el desarrollo de una o varias actividades que tienen una dimensión física, es decir ocupan un espacio, y una dimensión organizativa o de funcionamiento. El entramado institucional que sustenta ese funcionamiento es complejo. La Real Colegiata alberga al menos 13 instituciones o entidades de estatus jurídico diferente. El Cabildo, el Instituto Secular Sacerdotal de San Isidoro (Instituto Isidoriano) y la Cátedra de San Isidoro (de la que dependen la Editorial y la Librería Isidorianas) constituyen las instituciones rectoras. Existen además seis asociaciones religiosas con sede en la Colegiata: la Muy Ilustre, Real e Imperial Cofradía del Milagroso Pendón de San Isidoro, Guardia y Oración, Apostolado de la Oración, Adoración Nocturna Masculina de León, Adoración Nocturna Femenina de León y la Sacramental y Penitencial Cofradía de Nuestro Padre Jesús Sacramentado y María Santísima de la Piedad Amparo de los Leoneses. En la Real Colegiata tiene su sede también la Coral Isidoriana. A estas instituciones es preciso añadir la Casa de Espiritualidad (empresa dada de alta en el Registro Oficial de Establecimientos Hosteleros de Castilla y León) y Museos de la Real Colegiata de San Isidoro. Finalmente hay que tener en cuenta también la presencia del Instituto Bíblico y Oriental, una fundación autónoma y no vinculada con el Cabildo que cuenta como patronos con la Fundación Eulen y Caja España, y que se ubica en las dependencias de la Colegiata, en espacios cedidos mediante un contrato de arrendamiento.

La principal función de la Real Colegiata es la religiosa. Están afectos a este uso la Basílica con sus capillas (Santo Cristo y Santo Martino) y dependencias anejas (Sacristía y Sala de Guardia de la Adoración Nocturna) y la zona denominada del "Hogar Isidoriano", que cuenta en planta baja y primera planta con múltiples salas donde tienen sus reuniones las distintas asociaciones religiosas. La Basílica permanece abierta de 7:30 a 24:00, tiene un amplio horario de misas y actos litúrgicos y detenta, desde hace siglos, privilegio de exposición permanente del Santísimo. San Isidoro de León celebra además misas de acuerdo al Rito Hispano-Mozárabe o Isidoriano-Visigótico, coincidiendo con fiestas especiales o también a petición de colectivos, particularmente académicos y grupos de peregrinos. Este rito fue restaurado en la Colegiata en 1966, un privilegio excepcional pues sólo otras tres diócesis go- 
Gráfico 2. Real Colegiata de San Isidoro de León. Cartografía de usos. Planta baja.

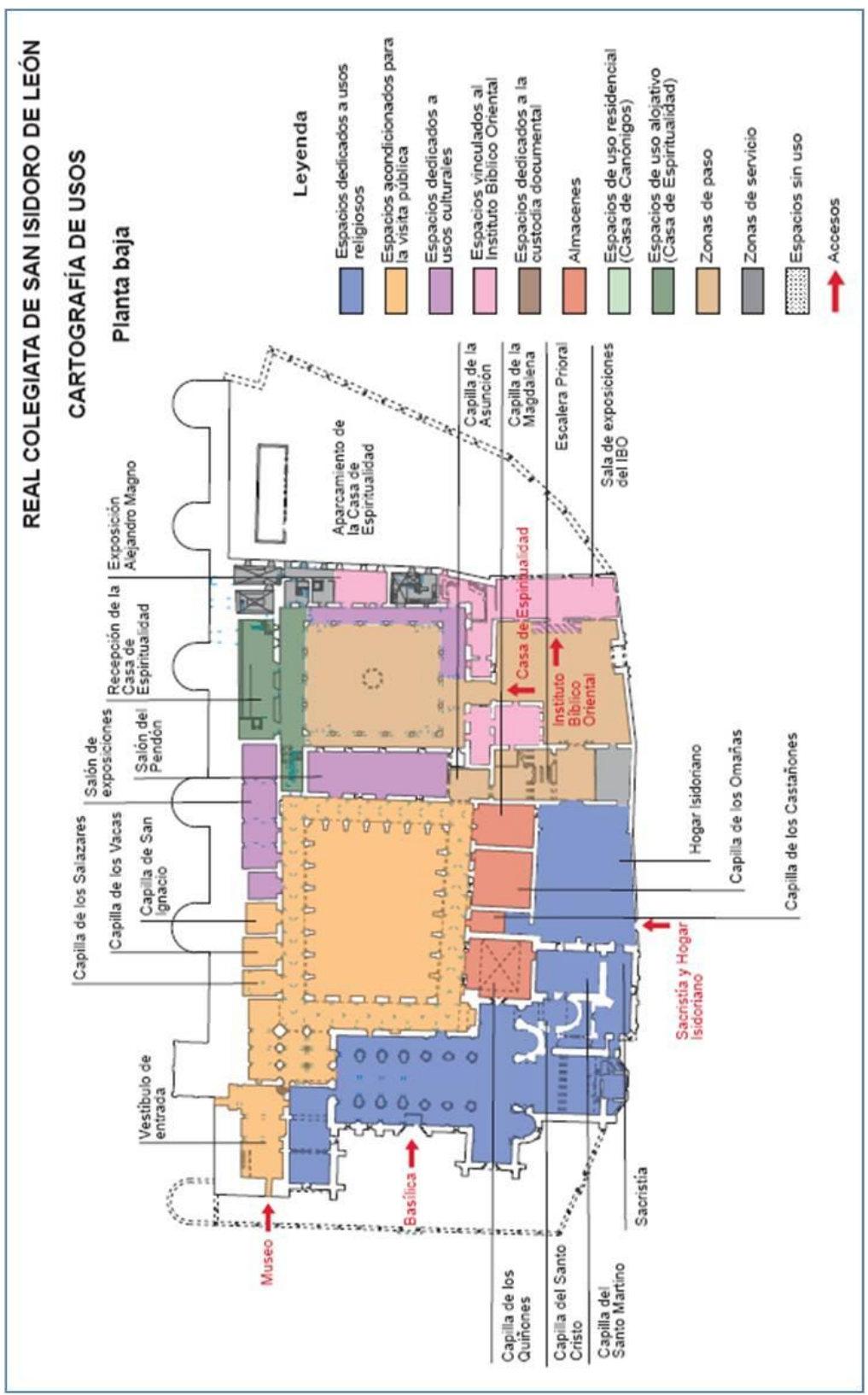

FuENTE: Proyecto "La Colegiata de San Isidoro de León. Estudio del funcionamiento turístico y cultural del Conjunto". Fundación Caja Madrid. 
zaban por aquel entonces de esta concesión: Toledo, Granada y Salamanca. Años después la Santa Sede extendió el rito mozárabe a toda la Iglesia de España y se revisó publicándose los textos depurados. Actualmente la Basílica facilita este texto a cada uno de los asistentes a la liturgia visigóticoisidoriana que se celebra en el templo (VIÑAYO, 2007).

Aunque evidentemente no hay registro de fieles, el trabajo de campo realizado el día 25 de agosto de 2010 puso de manifiesto que a lo largo de toda la jornada, desde las 7:30 (hora de la primera misa) hasta las 21:00 horas fueron 356 los fieles (población local no turista) que entraron en la iglesia para rezar, hacer una visita al Santísimo o escuchar misa. Esta afluencia de personas es constante a lo largo de todo el día, aunque se intensifica en los horarios de misa. La basílica registra también un importante uso turístico, pues su entrada es libre y gratuita. De hecho, aunque el templo mantiene un importante nivel de uso relacionado con el culto, el mayor volumen de entradas de personas diariamente tiene que ver con la visita al conjunto monumental. En el recuento efectuado el día 25 de agosto de 2010 se contabilizaron hasta 1.420 entradas de visitantes / turistas.

La función museística resulta clave para el funcionamiento del conjunto, pues genera ingresos que han permitido acometer obras de conservación a lo largo de los años en que el Museo ha venido estando abierto al público. El Panteón Real abrió sus puertas a la visita pública en 1958 y varios años más tarde, en 1962, se abre además el Museo (en la Cámara de Doña Sancha) con exposición de las piezas del Tesoro. Actualmente, la zona de la Colegiata acondicionada como Museo (ya sea con funciones expositivas o de servicio) se estructura en seis espacios, situados en tres plantas. La superficie útil ocupada por estos usos es de $2.326,51 \mathrm{~m}^{2}$, de los cuales $1.729,36 \mathrm{~m}^{2}$ son espacio acondicionado para la visita, $438 \mathrm{~m}^{2}$ son almacenes y otros espacios de servicio del Museo y $158 \mathrm{~m}^{2}$ espacio de servicios para el visitante (aseos, entrada, taquilla, librería, etc.).

En planta baja se ubica un vestíbulo de entrada (venta de billetes y librería), el Panteón Real (con las pinturas románicas y 12 tumbas que contienen 23 cuerpos de reyes y reinas de León) y el claustro procesional (con varias capillas acondicionadas y exposición de lápidas, capiteles y otros restos de escultura romana, románica y gótica provenientes de distintas partes de la Colegiata). En la primera planta, a la que se accede por una estrecha escalera de caracol, se sitúa la Cámara de Doña Sancha o Tribuna Real (que ocupa una sala abovedada de no muy grandes dimensiones en la que se exponen las 46 piezas más valiosas del Patrimonio mueble de la Colegiata como el Arca de San Isidoro, la Arqueta de los Marfiles, el Cáliz de Doña Urraca....) y la Biblioteca (sala renacentista de bóveda estrellada con vitrinas en las que se 
expone y almacena la documentación histórica (incunables, cantorales, códices...). Finalmente en el sótano se encuentran los aseos y el almacén.

A fecha de octubre de 2011 el espacio disponible para atender las necesidades del visitante era mínimo y resultaba a todas luces insuficiente dado el volumen actual de la demanda y sus requerimientos. Además los espacios acondicionados para la visita presentaban algunos problemas relativos a aspectos como la accesibilidad y movilidad interna (escalones, estrecha escalera de caracol de doble sentido de circulación,...), superación de la capacidad de acogida de los espacios clave de visita como el Tesoro o el Panteón en momentos de alta afluencia de visitantes (hacinamiento, saturación turística...), humedades en diferentes salas, adecuación museográfica y discurso interpretativo anticuados, envejecimiento de las instalaciones (almacén, aseos, oficinas...).

Estrechamente vinculada a la función museística se encuentra la custodia documental (archivo y biblioteca). La Real Colegiata de San Isidoro atesora un rico y valiosísimo patrimonio documental y ha generado además a lo largo de su dilatada historia una extensa documentación relacionada con la actividad de la propia institución. El Archivo-Biblioteca, como así se llama, ocupa tres espacios: la Biblioteca Histórica (abierta a la visita), el depósito de la Biblioteca Moderna o de Cátedra y la Sala de Investigadores. El Archivo o Biblioteca Histórica se ubica en la primera planta de un edificio independiente, construido a comienzos del siglo XVI. La sala donde se guardan y exponen los fondos fue restaurada en 1962 y en ella se custodian varias colecciones: de códices (manuscritos, algunos de ellos en pergamino), de pergaminos (documentos en hojas sueltas y legajos: bulas pontificias, documentos reales, eclesiásticos y particulares), de incunables (de 1450 a 1500), de "Libros antiguos, raros y curiosos", cantorales y diversas cajas que contienen documentación generada por la Colegiata y sus instituciones. Por su parte la Biblioteca nueva o de Cátedra se sitúa sobre una sala anexa y en ella se guardan los fondos modernos vinculados a la actividad de la Cátedra de San Isidoro, el archivo fotográfico y el inventario de patrimonio de la Colegiata. Por último en la antesala de esta biblioteca nueva o de Cátedra se ubica un pequeño despacho donde se atiende a los investigadores (con un seis mesas para la consulta de libros y documentos) y se custodian los documentos de gestión diaria (el archivo de oficina): autorizaciones para la consulta de documentos, autorizaciones de grabación y toma de fotografías, consultas, informes de contabilidad y gestión, etc.

Las funciones relacionadas con tareas de investigación y formación también están presentes en la Real Colegiata de San Isidoro. Dichas funciones están asociadas a la actividad de dos instituciones: la Cátedra de San Isidoro, 
una de las instituciones rectoras de la Real Colegiata y el Instituto Bíblico y Oriental (fundación ajena e independiente de la Real Colegiata). La Cátedra de San Isidoro, creada en 1945, es una fundación, adscrita al Obispado en principio, y luego a la Colegiata. Sus fines son el "estudio de la doctrina de San Isidoro, de su época y de su influencia en la cultura eclesiástica, española y en la civilización cristiana, la formación de investigadores y la organización de seminarios, cursos y conferencias sobre San Isidoro". Se financia con fondos de mecenas. Durante 43 años, dirigida por Don Antonio Viñayo, abad de la Colegiata y director también del Museo-Archivo y Biblioteca por esos años, tuvo una intensa actividad con la realización de publicaciones y la organización de conmemoraciones, asambleas, congresos, conferencia y jornadas de diverso tipo ${ }^{3}$. La Cátedra ha publicado algunas de las conclusiones de estos encuentros en colaboración con otras instituciones (Diputación Provincial de León, Universidad de León, etc.).

Por su parte el Instituto Bíblico y Oriental (IBO), con sede en las dependencias del Conjunto Monumental, es sin embargo una institución independiente de la Real Colegiata. El Instituto es una entidad cultural patrocinada por la Fundación Eulen y Caja España que cobró forma en León en el año 2003, cuando el sacerdote Jesús García Recio trajo a la ciudad el legado que había recibido como alumno distinguido del profesor Van Dijk, erudito holandés experto en la cultura de Mesopotamia. Dicho legado se compone de más de 10.000 libros y revistas especializados en temas orientales, y casi 1.000 piezas y objetos arqueológicos. El objetivo del instituto es el "estudio y la reflexión acerca de los fundamentos del mundo actual a partir de la Biblia, en cuanto raíz de la civilización cristiana occidental, y del Oriente que puso los cimientos de la cultura que se va haciendo común". El Instituto cuenta con museo, biblioteca y desarrolla además diversas actividades (excavaciones, cursos, conferencias, seminarios, aula juvenil). El museo del IBO, abierto al público con acceso desde la Plaza del Santo Martino, alberga una importante colección de objetos relacionados con la Biblia y Oriente Próximo. La biblioteca tiene un fondo de 10.000 volúmenes de las disciplinas relacionadas con el Oriente Bíblico, el Antiguo y el Nuevo Testamento. Por último las actividades culturales, formativas y de investigación están re-

\footnotetext{
${ }^{3}$ Por ejemplo: XIV Centenario del nacimiento de San Isidoro (1960), I Milenario de la Biblia Visigótica (1960), IX Centenario de la llegada de San Isidoro a León (1963), XIII Centenario de la muerte de San Fructuoso, fundador de la Tebaida leonesa (1965) y la celebración del XIX Centenario de la creación de la Legio VII Gemina, fundadora de la ciudad de León (1968), I Coloquio Internacional sobre Historia de la Minería Hispana e Iberoamericana (1970), Semana Bíblica para sacerdotes y religiosos (1973), Congreso Internacional referido a Santo Martino y su tiempo (1985), Congreso Internacional sobre el Monacato (1988), I Jornada sobre Minería y Tecnología en la Edad Media Peninsular (1995).
} 
lacionadas con viajes a Oriente, cursos de lenguas muertas (sumerio, acadio, egipcio, ugarítico, hebreo, copto, etiópico, griego, latín y armenio), seminarios, conferencias y un taller-aula juvenil (para niños entre 7 y 11 años).

Buena parte del Conjunto Monumental de la Real Colegiata cumple también funciones de alojamiento, de carácter permanente (Residencia de Canónigos) y de tipo hotelero (Casa de Espiritualidad). En la Residencia de Canónigos viven los canónigos de la Colegiata, pero ésta cuenta también con la llamada Casa de Espiritualidad que surge de la remodelación en 2005 de las dependencias utilizadas para la realización de ejercicios espirituales. De ahí conserva su nombre y, en buena medida aún, el fin para el que su día proyectaron la rehabilitación los canónigos del cabildo. No obstante, su condición legal es la de una empresa de alojamiento, un hotel de tres estrellas dado de alta en el Registro de Establecimientos Turísticos de la Junta de Castilla y León. Cuenta además con servicio de restaurante que ofrece régimen de pensión completa a los visitantes alojados en la Casa, pero también sirve un menú del día para clientes externos. Tiene capacidad para alojar al día a unos 52 viajeros (en 37 habitaciones), lo que supone capacidad para atender más de 15.000 pernoctaciones anuales. Además ofrece servicios de alquiler de salas para celebración de reuniones.

En relación a la actividad cultural, cabe señalar que si bien el Cabildo de la Real Colegiata de San Isidoro no tiene un programa cultural propio fijo (asumidas hace años por la Cátedra de San Isidoro), la Real Colegiata acoge actos culturales de distinto tipo organizados por instituciones externas, entre ellos algunos Cursos de Verano de la Universidad de León. De hecho en el conjunto existen varios espacios destinados a usos culturales: el Salón del Pendón (antiguo refectorio ubicado en el claustro procesional), el Salón San Isidoro, las aulas de la planta primera, la sala de exposiciones de la planta baja (un antiguo almacén rehabilitado que acoge exposiciones temporales), la Capilla de Quiñones (en la planta baja del Claustro) y también se utiliza para actos culturales todo el espacio del Claustro Procesional bajo. Estos actos (teatro, conciertos, Las Cabezadas, actos religiosos...) se celebran al aire libre y fuera del horario de visitas al Museo con acceso desde la Plaza del Santo Martino. Los actos culturales que mayor repercusión tienen están vinculados con la Universidad de León que alquila espacios de la Real Colegiata de San Isidoro como sede de algunos de sus Cursos de Verano. En 2011 la oferta de Cursos de Verano de la Universidad de León contemplaba la celebración de siete cursos durante varias semanas de los meses de julio y agosto.

Como se ha señalado anteriormente las actividades de la Cátedra de San Isidoro han tenido un importante protagonismo en la vida cultural de la Co- 
legiata, aunque hayan disminuido en los últimos años. Actualmente, la $\mathrm{Li}$ brería y Editorial Isidoriana, que dependen de esta institución, constituyen el aspecto más visible de su actividad. En la librería, ubicada en la recepción del Museo se venden tres tipos de productos: guías y libros de historia y arte (ediciones propias de la Editorial Isidoriana y otras obras editadas por el servicio de Ediciones de la Universidad de León u otras editoriales), ediciones facsimilares de algunos de los incunables que custodia la Biblioteca Capitular (Biblia Visigótico Mozárabe, etc.) y artículos de regalo (marcapáginas, imanes, reproducciones en general, postres, colgantes, postales, CDs, calendarios...).

Finalmente dentro de la actividad cultural de la Real Colegiata hay que destacar también la actividad de la Coral Isidoriana de León. Colabora activamente en el culto (normalmente en la misa conventual del primer viernes de mes) y en los actos principales de la Colegiata. La coral ofrece conciertos, tanto en la provincia de León como en otras ciudades de España y participa en Festivales y Certámenes. Cada año cuida especialmente el Concierto que ofrece en la Basílica la tarde del Sábado Santo (único concierto que ofrece al año en el interior del templo). La Coral tiene su sede en la Colegiata y utiliza como local de ensayos una de las salas del llamado Hogar Isidoriano.

\section{III.2. La dimensión turística de la Real Colegiata.}

Dado el valor histórico cultural de la Real Colegiata y su monumentalidad, la proyección turística de este hito patrimonial es indudable. Desde que en 1958 se abrieran al público los primeros espacios (Panteón Real) la afluencia de visitantes no ha hecho más que aumentar. Hoy en día además la dimensión turístico-cultural del conjunto se refuerza con el funcionamiento del Instituto Bíblico y Oriental (con un museo y una activa programación de eventos) y la Casa de Espiritualidad, que si bien se encuentra orientada a un segmento de mercado de marcado carácter religioso, cuenta también con clientes de turismo de reuniones y negocios (reuniones de empresa, congresos, cursos...).

Los datos globales de afluencia de visitantes, tanto la entrada al Mueso como los viajeros alojados en la Casa de Espiritualidad, señalan la importancia que adquieren estas actividades en el funcionamiento diario del conjunto. En 2010 fueron 101.782 los visitantes del Museo y se registraron un total de 3.904 pernoctaciones en la Casa de Espiritualidad. A medio plazo el potencial de crecimiento de la Casa de Espiritualidad es alto pues sus niveles de ocupación por plazas son bajos y dispone de importantes ventajas competitivas en el contexto hotelero de la ciudad (localización en edificio singular, ubicación céntrica, belleza de espacios comunes, aparcamiento gratuito, tari- 
fas competitivas....). No ocurre lo mismo en cambio con el Museo, que con una media de 104.299 visitas al año durante el periodo 2000-2009 se configura ya como uno de los elementos patrimoniales más visitados de la ciudad de León, sólo superado por la Catedral y el MUSAC. A escala nacional, si bien estos 100.000 visitantes del Museo de la Colegiata no son muchos, dentro del ámbito de Castilla y León permiten su incorporación a un segundo nivel de hitos visitados (monumentos y museos) generalmente sólo superados por los grandes conjuntos catedralicios.

Los datos que emanan del registro histórico de entradas del Museo, así como los resultados de la encuesta realizada a los visitantes, permiten realizar una caracterización de los rasgos básicos de la afluencia turística de la Real Colegiata. De esta manera, en relación a la evolución del volumen de visitas cabe señalar que el primer dato de visitas disponible corresponde al año 1958: aproximadamente 2.400, según los libros de contabilidad. Desde entonces se ha registrado un crecimiento vertiginoso: 27.805 visitas ya en 1970, 42.754 en 1980, 65.584 en 1990 y 107.166 en el 2000, además de las ya referidas 101.782 durante 2010. Este crecimiento se enmarca dentro de las profundas transformaciones socioeconómicas que han afectado a España en el último medio siglo, transformaciones que han impulsado un notable crecimiento de los flujos turísticos y, más recientemente, de los flujos asociados a los lugares del patrimonio. Sin embargo, durante la última década la afluencia de visitantes al Museo de la Colegiata está experimento una dinámica menos positiva, sobre todo si se compara con la evolución del turismo a nivel de la ciudad de León. Este fenómeno también se constata en otros de los grandes hitos monumentales y destinos turísticos del interior (el Alcázar de Segovia respecto a Segovia, Santo Tomé respecto a Toledo, etc.).

Por tipo de visitantes cabe señalar que durante el año 2009, las visitas se repartieron del siguiente modo: 57.192 visitas individuales, el 62,93\% de la afluencia total; 31.417 visitas colectivas, el 23,57\%; y 12.259 visitas gratuitas, el 13,49\% restante. Dada la problemática adscripción de las visitas gratuitas a fórmulas de viaje individual o colectivo, resulta difícil determinar con exactitud la dinámica de estas dos grandes fórmulas de viaje. Si sólo nos atenemos a las entradas de pago, el 68,16\% de las visitas efectuadas entre 1976 y 2009 corresponden a visitas individuales y el 31,84\% a colectivas. Salvo en algunos años excepcionales este reparto permanece bastante estable en todo el periodo considerado. No obstante se observa que en los últimos años la visita individual se está comportando mejor que la colectiva, en todo caso un comportamiento ligeramente más positivo dentro de una dinámica general recesiva.

La distribución mensual de la afluencia se sitúa entre dos meses extremos: 
enero (2,45\% de las visitas registradas en 2009) y agosto (17,7\%). Entre estos dos extremos es posible diferenciar cuatro temporadas turísticas:

Gráfico 3. Evolución del número de visitas (1976-2009)

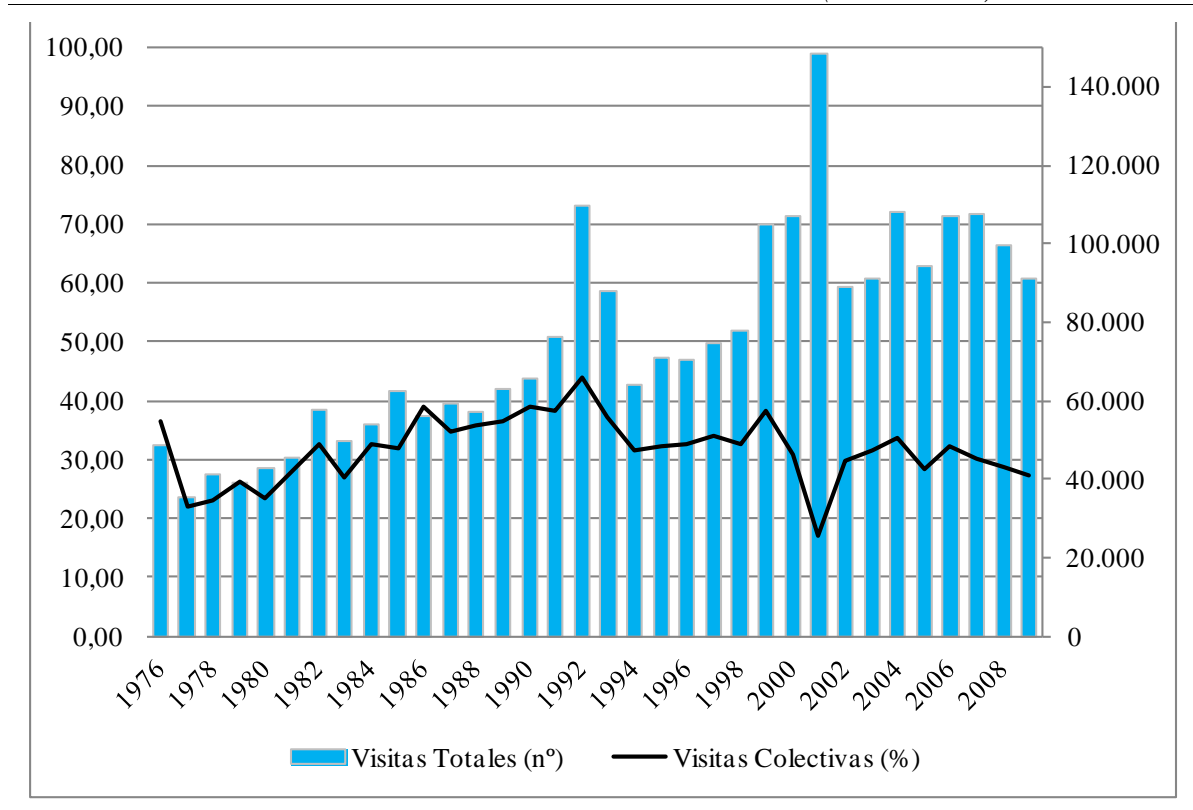

Visitas totales, escala derecha; visitas colectivas, escala izquierda.

FUENTE: Real Colegiata de San Isidoro. Registros de visitantes del Museo.

1) Temporada baja, asociada a los meses más nítidamente invernales: enero $(2,45 \%)$ y febrero $(3,25 \%)$;

2) Temporada media baja, que se sitúa a medio cambio entre las temporadas bajas y media-alta (de una parte, marzo reúne el 5,28\% de la afluencia anual; en el otro lado del año, noviembre representa el 5,4\% y diciembre el 4,25\%);

3) Temporada media alta, con un primer periodo que transcurre entre la Semana Santa y julio (abril-9,12\%, mayo-12,11\%, junio-10,11\% y julio-11,06\%) y un segundo periodo asociado al tránsito entre el verano y el otoño (septiembre-10,31\% y octubre- $9,01 \%$ );

4) Temporada alta, básicamente asociada a agosto $(17,7 \%)$, el mes vacacional por excelencia de los españoles. 
La distribución por tipo de visita / entrada muestra diferencias mucho más significativas. La visita individual presenta un reparto muy similar al correspondiente a la afluencia general, en buena medida debido a que constituye el componente principal de dicha afluencia. En cambio, la distribución mensual de las visitas colectivas resulta mucho más singular. A grandes rasgos, es posible diferenciar dos temporadas bajas que corresponden al invierno y al verano y otras dos temporadas altas, asociadas a la primavera y, en mucha menor medida, el otoño. Esta distribución responde tanto a las pautas de movilidad de los grupos escolares como de los grupos comerciales de agencia, que ofertan sobre todo circuitos urbano-culturales.

Gráfico 4. Distribución mensual de las visitas (\%) por tipo de visita / entrada 2009

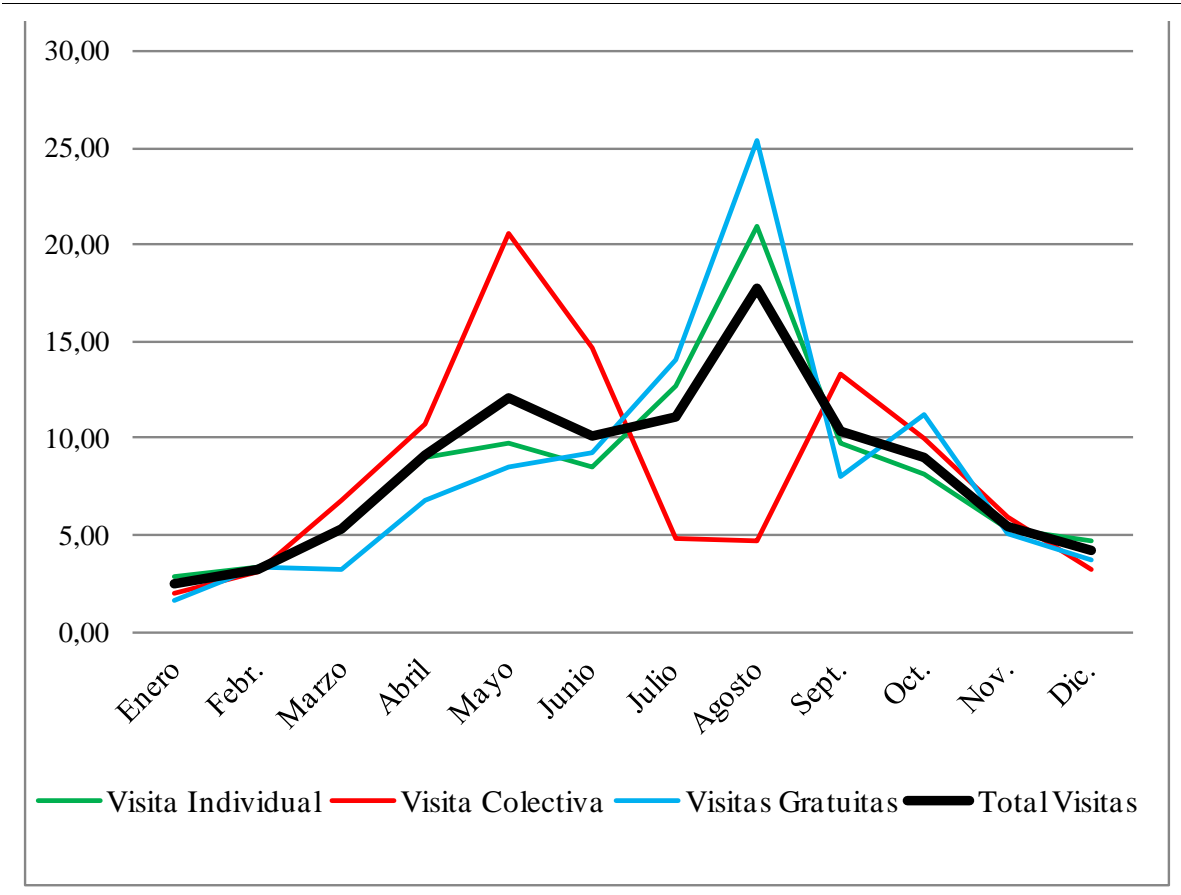

FUENTE: Real Colegiata de San Isidoro. Registros de visitantes del Museo

En relación a la caracterización de los visitantes los resultados de la encuesta realizada en verano de 2010 mostraron varios aspectos interesantes. En líneas generales, el perfil socioeconómico de los visitantes encuestados se corresponde con el modelo general observado en las ciudades históricas del interior peninsular. Las variaciones específicas derivan de los parámetros espacio-temporales de realización de la encuesta. En primer lugar, esta encues- 
ta se centra en los visitantes del Museo de San Isidoro, que presentan una mayor orientación y capital cultural que el conjunto de los visitantes de la ciudad de León. En segundo lugar, se trata de una encuesta realizada en el mes de agosto, cuyos resultados difícilmente se pueden extrapolar a la totalidad del año. Agosto es el mes más nítidamente vacacional con unas características especiales en cuanto a viajes y viajeros, en todo caso diferentes a las existentes en otras temporadas turísticas del año.

La residencia de los visitantes es mayoritariamente nacional, un 83,33\%, quedando limitado los turistas extranjeros al 16,67\% restante. Dentro de los visitantes nacionales las Comunidades Autónomas que más visitantes aportan son Madrid (27,2\% de los residentes en España), Andalucía (17,6\%), Castilla y León $(11,2 \%)$, País Vasco $(8,8 \%)$ y la Comunidad Valenciana $(8,8 \%)$. El peso de cada procedencia depende de factores como la potencia demográfica (Andalucía, Comunidad Valenciana, etc.) y la proximidad geográfica (resto del territorio de Castilla y León, etc.). Cuando ambos factores actúan en conjunto la presencia de los visitantes de este mercado de origen tiende a ser muy elevado, caso de los residentes en la Comunidad de Madrid. Por su parte dentro de los visitantes extranjeros existe un absoluto predominio de los residentes en otros países de Europa (69,57\% de los extranjeros) seguidos de los americanos (26,09\%), fundamentalmente de Latinoamérica.

El nivel de estudios de los visitantes es muy alto: el $86 \%$ de los encuestados dice contar con estudios universitarios. Esta circunstancia se refleja en las categorías profesionales identificadas. En un 67\% de los casos corresponden a ocupados superiores con una fuerte importancia de los profesores (33\%), seguidos de los abogados (13\%). Dentro de la población económicamente no activa destaca el conjunto de amas de casa y jubilados (10\%), seguidos de los estudiantes (7\%). Estos datos son interpretables a partir de dos realidades subyacentes. De una parte, la asociación de las visitas a espacios patrimoniales con visitantes con notable "capital cultural". La lectura del patrimonio resulta compleja, se necesitan una serie de claves de interpretación que se suelen adquirir en el sistema educativo, donde la mayoría de las personas adquieren su capital cultural. Contar con este capital predispone hacia la visita a espacios patrimoniales en tanto que son comprendidos y apreciados. De ahí la importancia de visitantes con elevado nivel educativo y profesiones vinculadas al manejo de información, en especial vinculados a la enseñanza y con fuerte orientación hacia las humanidades y ciencias sociales. Junto a esta realidad subyace un problema operativo en este tipo de encuestas: en general dentro de un grupo de viaje tiende a responder el cuestionario la persona con mayor nivel educativo; estas personas se erigen como portavoces del grupo en tanto que suelen ser los miembros más habituados al es- 
quema de comunicación inherente a una encuesta. En este sentido, sería más apropiado afirmar que en el $86 \%$ de los grupos de viaje entrevistados había al menos una persona con estudios universitarios y que en el $67 \%$ de dichos grupos una persona tenía una ocupación vinculada a dicho nivel de estudios.

En relación a las condiciones de la visita al Museo llama la atención cómo existe, al igual que en buena parte de los hitos turístico-patrimoniales del país, un importante volumen de visitantes que repiten visita. En concreto un $21,08 \%$ de los visitantes encuestados ya habían estado en el Museo de San Isidoro. A estos hay que sumar los visitantes que ya habían estado antes en la Colegiata pero no habían accedido a las dependencias del Museo, que representan otro $15,64 \%$ de los encuestados.

Respecto al conocimiento previo del conjunto, la referencia más popular del conjunto monumental corresponde a las pinturas románicas del Panteón, aspecto conocido de forma previa a la visita por el $93,55 \%$ del conjunto de encuestados reseñados. La propia asociación de la Colegiata con el Panteón de los Reyes de León también constituye un referente ampliamente reconocido, en un porcentaje que alcanza el $84,95 \%$. Por el contrario, las otras dos referencias por las que se indagaba resultaron mucho más minoritarias: tan solo el $38,71 \%$ reconoce tener indicaciones sobre el fondo documental y el $35,48 \%$ sobre el tesoro basilical.

Finalmente en términos de valoración los visitantes encuestados valoraron muy bien las condiciones de visita del Museo. En una escala de 1 a 7, equivaliendo el 1 a una valoración muy mala / insuficiente y el 7 a una elevada satisfacción con las condiciones percibidas, se obtiene un valor promedio de 5,82. No obstante las puntuaciones obtenidas en cada uno de estos aspectos (P. 10) varían notablemente: Estado de conservación del monumento (6,26 sobre 7, sin lugar a dudas el aspecto mejor valorado), Dimensiones y acondicionamiento de la zona de recepción de la visita $(6,4$, también un aspecto muy bien valorado), Adecuación museográfica $(6,12)$, Precio de la entrada $(5,14)$ y Baños $(4,1)$.

\section{CONCLUSIONES Y CONSIDERACIONES FINALES.}

En buena medida la investigación española en Geografía del Turismo se ha centrado sobre dos ámbitos de trabajo: los recursos y los destinos turísticos. En tanto que factores de atracción, los recursos son el elemento central de cualquier lugar que sea o aspire a convertirse en un destino turístico. Sin embargo, si la reflexión conceptual sobre estos últimos se asienta sobre bases sólidas (véase por ejemplo el trabajo de BARRADO, 2004), en las aproximaciones al estudio sobre los recursos se adolece de cierta falta de sustento 
teórico que contrasta con los debates suscitados al respecto en otros países (LEW, 1987; LEIPER, 1990). Las reflexiones recogidas en este texto delimitan el concepto de "hito patrimonial" en tanto que objeto de investigación. Se considera hito patrimonial a aquel recurso turístico-patrimonial (de naturaleza inmueble) que se integra dentro de las atracciones turísticas activas de un destino, es decir está acondicionado para un uso turístico, cuenta con un programa de comunicación explícito y constituye un referente turístico del lugar donde se sitúa. Ahora bien, el análisis de la realidad castellano-leonesa pone de manifiesto la existencia de dificultades operativas para la identificación de los hitos patrimoniales, dificultades que están implícitas en los estudios de base del Plan de Impulso al Turismo Cultural e Idiomático (TURESPAÑA, 2001) en los que se plantea la diferencia no siempre nítida entre patrimonio, producto cultural y oferta cultural.

Una de estas dificultades, quizás la más importante, está relacionada con la condición de referentes turísticos. Esta consideración alude a la asociación de hitos patrimoniales con la imagen o imágenes turísticas del destino, pero también tiene que ver con la afluencia de visitantes. Por tanto, a nivel operativo, la variable afluencia turística aparece como un elemento básico en la adscripción de museos, zonas arqueológicas, monumentos y conjuntos monumentales a esta categoría de hitos patrimoniales. En Castilla y León la realidad nos habla de un limitado número de elementos visitables que superan los 100.000 visitantes año (Alcázar de Segovia, Catedrales, Muralla de Ávila, Real Colegiata de San Isidoro de León, Palacio Real de La Granja...). En cambio, la mayoría de los espacios patrimoniales acondicionados para la visita tienen reducidos niveles de afluencia turística, sin apenas llegar a los 30.000 visitantes anuales ${ }^{4}$. En su contexto de referencia a nivel de región y/o destino estos niveles de visita permiten caracterizar hitos patrimoniales pero resulta más cuestionable su adscripción cuando se comparan con los grandes referentes turísticos del país, que registran cifras millonarias de visitantes (Alhambra de Granada, Mezquita de Córdoba, Catedral de Sevilla, Catedral de Santiago de Compostela, Sagrada Familia de Barcelona...).

\footnotetext{
${ }^{4}$ Tomando como referencia los datos de 2009, superan los 30.000 visitantes espacios como el Museo Patio Herreriano de Valladolid (60.110) y, a mucha distancia, la Casa de los Deanes-Museo de Ávila (32.720) y la zona visitable del antiguo convento de San Marcos de León (30.927). Entre 30.000 y 20.000 se encuentran el Museo Numantino de Soria (24.595), el Palacio de Fabio Nelli-Museo de Valladolid (24.417) y la Casa de los Abarca-Museo de Salamanca (20.913); por debajo de 20.000 el Museo de Zamora (19.922), la Casa de Cervantes de Valladolid (17.760), la Casa de Miranda-Museo de Burgos (17.546), el Monasterio de Santo Tomás de Ávila (15.462), la Casa del Cordón-Museo de Palencia (8.781), la iglesia de San Juan de los Caballeros de Segovia-Museo Zuloaga (5.778) y el yacimiento de TorralbaAmbrona (5.560), entre muchos otros.
} 
Respecto a la gestión turístico-patrimonial, la realidad analizada pone de manifiesto la complejidad de abordar la relación de los hitos y los destinos de los que forman parte. A nivel de hito patrimonial (monumento, museo, sitio o zona arqueológica, conjunto monumental, etc.) se aprecian avances en relación a los planteamientos e instrumentos de gestión (planes y programas operativos) y las actuaciones realizadas durante los últimos tiempos. Se trata de una escala de trabajo acotada y abarcable en la que se empiezan a tratar desde una unidad de gestión y con mayor o menor fortuna los aspectos relacionados con la gestión de la visita (gestión de flujos de visitantes, comunicación, articulación de oferta turístico-cultural, control de impactos...). Sin embargo la integración del hito o hitos patrimoniales y el destino en el que se insertan constituye un ámbito de trabajo aún poco desarrollado. Esa integración exigiría tomar en consideración diferentes niveles de trabajo: el nivel interno del hito patrimonial (ya considerado), el nivel del entorno inmediato (gestión de la accesibilidad, control del aparcamiento, gestión de colas...) y el nivel del destino en su conjunto al objeto de crear ejes temáticos y facilitar una lectura integrada de la realidad patrimonial local (entradas conjuntas, señalización homogeneizada, rutas temáticas...).

La localización de los hitos patrimoniales introduce diferencias notables en su dimensión turística. A escala territorial existen divergencias entre el componente cultural del turismo urbano y del turismo de rural. Si el primero presenta una larga trayectoria como objeto de investigación, con estudios específicos para algunas de las ciudades Patrimonio Mundial (TROITIÑO et AL., 2009; TROITIÑO, 2010), el significado turístico de los hitos patrimoniales activos a efectos del turismo rural resulta mucho menos conocido. En el ámbito urbano la gestión del patrimonio acondicionado para la visita se realiza en clave turística asentándose sobre parámetros más o menos controlados en relación al perfil de la demanda, el comportamiento de los visitantes en destino, la estacionalidad de la afluencia, etc. Se ha trabajado además en destinos más o menos consolidados o en fase de expansión con volúmenes de visitantes importantes y crecientes durante las últimas dos décadas (por ejemplo, las grandes ciudades del Patrimonio Mundial). En cambio en el ámbito rural el trabajo se ha planteado en clave de desarrollo local. Se pretendía convertir el patrimonio en vector de desarrollo, pero con escaso conocimiento del mercado turístico. De esta manera se han realizado multitud de iniciativas de "puesta en valor turístico" de recursos patrimoniales que han resultado infructuosas dado su poco sentido en el contexto turístico territorial en el que se insertaban (flujos más minoritarios que los de turismo urbano, estacionalidad más marcada, posición secundaria o complementaria del patrimonio histórico y cultural como recurso turístico en un contexto de motivaciones diversas, etc.). 
Los resultados obtenidos también muestran que existen variaciones notables en el tratamiento turístico de cada tipo patrimonial. Existe cierta homogeneidad en relación a la gestión de la visita que se realiza en los conjuntos catedralicios y los museos dependientes de la administración regional. En cambio, se aprecia gran disparidad en ámbitos como monumentos y sitios arqueológicos. La musealización y adecuación de yacimientos y elementos monumentales de distinta entidad en muchas ocasiones se han financiado con programas de desarrollo rural configurándose una serie de iniciativas aisladas que carecen de una imagen homogénea como parte del producto turístico regional. Contrasta esta situación con las propuestas recogidas en el Plan PAHIS (2005) en relación a la articulación de una red regional de monumentos, pero también con la realidad de otras comunidades autónomas como Andalucía donde existen sendas redes de Conjuntos Arqueológicos (Carmona, Itálica, Baelo Claudia...) y Monumentales (Alcazaba de Almería, Alhambra de Granada...) dependientes del mismo servicio administrativo y con el mismo modelo de gestión; o Castilla-La Mancha con su red de Parques Arqueológicos (Carranque, Segóbriga, Alarcos...).

San Isidoro de León reúne las características que permiten su consideración como uno de los hitos patrimoniales más importantes de Castilla y León dada su larga trayectoria como recurso turístico de proyección en el mercado nacional e internacional y el número actual de visitantes y usuarios asociados con las funciones museística y alojativa. Ejemplifica bien la complejidad que encierra la gestión turística de hitos patrimoniales en los que se desarrollan funciones de distinto tipo, que en algunos casos coinciden temporal y espacialmente: culto, actividades pastorales, actividades culturales, museo, atención a investigadores, gestión de un establecimiento hotelero, etc. Por otra parte, a pesar de la importancia de la función turística (en relación al volumen de visitantes atendidos y los ingresos generados) en San Isidoro se aprecian dos rasgos que se repiten en otros hitos patrimoniales dependientes de la Iglesia. De un lado los usos turísticos aparecen minusvalorados respecto a las funciones prioritarias de las instituciones rectoras (en este caso el Cabildo) que están relacionadas con el culto y la pastoral. Y de otro, la gestión de un entramado tan complejo de actividades, y especialmente la gestión de un hotel y de un museo, puede llegar a desbordar a los responsables directos por cuestiones de disponibilidad de tiempo, dedicación y capacitación profesional. El desconocimiento de la realidad turística por parte de los gestores conlleva la adopción tradicional de una posición pasiva que se limita a resolver los problemas cotidianos (venta de entradas, mantenimiento y limpieza, seguridad). Sin embargo los problemas actuales relacionados con la visita pública del Museo y el manejo de la Casa de Espiritualidad demandan una gestión más activa. 
A fecha de octubre de 2011, los datos globales de afluencia de visitantes (entradas al Museo y viajeros alojados en la Casa de Espiritualidad) ponen de manifiesto la importancia del conjunto como referente turístico de la ciudad. El Museo es uno de los espacios patrimoniales que mayor afluencia de visitantes recibe a nivel de León. Sin embargo, se enfrenta a problemas derivados de la alta afluencia de visitantes en momentos puntuales y a la inercia de un modelo de gestión tradicional y poco profesionalizado. Los registros de visita muestran que los momentos de saturación turística son puntuales aunque no excepcionales. Dadas las condiciones actuales de la organización de la visita el número máximo de visitantes diario que se pueden atender en el Museo se estima en unas 840 personas en horario de verano (meses de julio y agosto) y 420 en las jornadas en que el conjunto permanece abierto con horario de invierno. En el año 2009, si bien el número medio de visitantes / día se situó en 250 personas, hubo 32 días en que se registraron cifras de afluencia superiores a las 500 personas día, llegándose a alcanzar los 856 visitantes el día 2 de mayo, jornada en la que el conjunto monumental estuvo abierto sólo 6 horas. Esa cifra tan alta de visitantes supuso que se concentraran alrededor de 140 visitantes/hora de media, es decir 3 grupos por hora y casi 50 personas por grupo. Es preciso tener en cuenta que estas cifras de afluencia máxima de visitantes resultan excesivas teniendo en cuenta las dimensiones de los espacios acondicionados para la visita (Panteón, Tesoro y Biblioteca) y las dimensiones de las zonas de conexión y paso entre esos espacios. En el Panteón Real la disponibilidad de superficie apenas alcanza los $2 \mathrm{~m}^{2}$ por persona cuando entran grupos numerosos (entre 35 y 40 personas).

Mantener la viabilidad económica de la explotación del Museo y la Casa de Espiritualidad constituye también un gran desafío para la gestión de este conjunto monumental. La Casa de Espiritualidad presenta unos niveles de ocupación bajos pese a que reúne una serie de características que la hacen tremendamente competitiva en el contexto de la oferta hotelera de León (ubicación en un edificio histórico y singular, localización céntrica y aparcamiento propio, precios competitivos, certificación de calidad, etc.). El Museo en cambio tiene una alta afluencia de visitantes lo que ha permitido generar un balance de explotación positivo que ha venido sirviendo para acometer tareas de mantenimiento y rehabilitación de algunos espacios. No obstante, si se acomete la remodelación integral del espacio expositivo y se produce un cambio en el modelo de gestión (plantilla, organigrama de funciones, personal de seguridad, etc.), los gastos corrientes asociados a esos cambios han de subir necesariamente. Eso exigiría plantear alternativas de gestión que contemplen distintas modalidades de visita (con distintas tarifas) en función de las posibilidades que ofrezca la remodelación del Museo. Todo ello teniendo en cuenta que el margen para aumentar el número de visitas es 
escaso debido al contexto turístico en el que se inserta (afluencia turística de León), a que ya tiene un elevado número de visitantes y a que la capacidad de acogida turística de los espacios clave de la visita (Panteón de Reyes) es reducida. De hecho, dadas las dimensiones de ese espacio la capacidad de acogida del Museo una vez remodelado cabe pensarse no será muy diferente a la del actual (al menos en lo concerniente a la organización de la entrada al Panteón): un máximo de alrededor de 850 visitantes/día en horario de verano continuo de casi once horas, es decir en torno a 200.000-250.000 visitantes anuales (variables en función del diseño del horario de apertura). En consecuencia, a medio plazo y dado el proceso de remodelación del Museo, el equilibrio que garantizaría una gestión económica sostenible de las actividades turísticas de la Real Colegiata estaría relacionado con el aumento de beneficios derivados de la actividad hostelera (aumentar la ocupación y visibilidad del establecimiento).

Pese a estos problemas, las actuaciones acometidas en la Real Colegiata de San Isidoro a lo largo de sus últimos cincuenta años de historia son especialmente loables en relación a los procesos de rehabilitación y conservación del edificio, actividad cultural y adecuación museográfica de su patrimonio mueble. En líneas generales la Real Colegiata constituye un ejemplo representativo de los problemas y desafíos que afectan hoy en día a la gestión turístico-cultural de los grandes hitos patrimoniales. Problemas que desbordan la capacidad de modelos de gestión de la visita que se van quedando desfasados frente a las demandas del visitante del siglo XXI.

\section{BIBLIOGRAFÍA Y OTRAS FUENTES DOCUMENTALES.}

BARRADO TIMÓN, D. (2004): «El concepto de destino turístico. Una aproximación geográfico-territorial». Estudios Turísticos, n ${ }^{\circ}$ 160, 45-68.

CEBRIÁN ABELLÁN, F.; GARCÍA GONZÁLEZ, F. (2010): «Propuesta metodológica para la identificación, clasificación y puesta en valor de los recursos territoriales del turismo interior. La provincia de Albacete». Boletín de la Asociación de Geógrafos Españoles, ${ }^{\circ}$ 54, 361-383.

Consejería De Cultura Y TURISMO - JunTa De CASTILla Y León (2005): Plan PAHIS 2004-2012 del Patrimonio Histórico de Castilla y León. Aprobado mediante Acuerdo 37/2005, de 31 de marzo, y publicado en el BOCYL n ${ }^{\circ} 65$, de 6 de abril de 2005.

Consejería De Cultura Y TuRismo - Junta De CAstilla Y León (2011): Base documental del Catálogo de Bienes de Interés Cultural. http://servicios.jcyl.es/pweb/portada.do, consultado el 01/10/2011.

García Hernández, M.; Calle Vaquero, M. De La; Mínguez García, C. (2011): «Capacidad de carga turística en conjuntos monumentales de España y México. Referencias teóricas y aproximación metodológica». 
Ponencia en VII Congreso Internacional de Turismo en el Caribe. Cozumel (México), Universidad de Quintana Roo, Servicio de Publicaciones, 389-406.

Instituto Geográfico Nacional; SAncho, J.; PANADERO, M. A. (dirs.) (2004): Atlas del Turismo Rural de Castilla-La Mancha. Madrid, Centro Nacional de Información Geográfica-IGN.

InSTITUTO GEOGRÁFICO NACIONAL (2008): Monografías del Atlas Nacional de España. Turismo en espacios rurales y naturales. Madrid, Centro Nacional de Información Geográfica-IGN.

JANSEN-VerbeKe, M.; PRIESTley, G.K.; Russo, A.P. (2008): Cultural resources for tourism. Patterns, processes and policies. Nueva York, Nova Science Publishers.

Jimeno MartíneZ, A. (2000): «Numancia: Pasado Vivido, Pasado Sentido». Trabajos de Prehistoria, vol. 57, $\mathrm{n}^{\circ}$ 2, 175-193.

LENO CERRO, F. (1993): Técnicas de evaluación del potencial turístico. Madrid, Ministerio de Industria, Comercio y Turismo, Secretaría General de Turismo / TURESPAÑA.

LEW, A. (1987): «A framework of Tourist Attraction Research» Annals of Tourism Research, vol. 14, $\mathrm{n}^{\circ}$ 4, 553-575.

LEW, A. (2002): «Atracción». En Enciclopedia del turismo (JAFARI, J. ed.). Madrid, Síntesis, 67-68.

LEIPER, N. (1990): «Tourist Attraction Systems». Annals of Tourism Research, vol. 17, $\mathrm{n}^{\circ} 3,367-384$.

LÓPEZ OLIVARES, D. (1998): La ordenación y planificación integrada de los recursos territoriales turísticos. Estudio práctico de un espacio de "desarrollo turístico incipiente”: el Alto Palancia (Castellón).Castellón, Ediciones de la Universitat Jaume I.

LÓPEZ Olivares, D. (2005): El sistema turístico en Nicaragua. Desarrollo turístico integrado para la Región del Norte. Departamentos de Estela y Nueva Segovia. Castellón, Ediciones de la Universitat Jaume I.

RICHARDS, G. (2001): «Development of cultural tourism and cultural attractions». En Cultural attractions and European tourism (RICHARDS, G., ed.). Oxon, CAB International, 3-29.

RICHARDS, G. (2002): «Tourism attraction systems. Exploring cultural behaviour». Annals of Tourism Research, vol. 29, $\mathrm{n}^{\circ}$ 4, 1.048-1.064.

TRoitiño VinueSA, M.A. y TROITIÑO TORRALBA, L. (2009): «Turismo y Patrimonio en Castilla y León: las ciudades Patrimonio de la Humanidad (Ávila, Salamanca y Segovia) como destinos turísticos de referencia». Polígonos. Revista de Geografía, no 19, 145-178.

TROITIÑO TORRALBA, L. (2010): «La funcionalidad turística de los recursos monumentales de las ciudades Patrimonio de la Humanidad: Ávila, Cuenca, Segovia y Toledo», en Dinámicas funcionales del turismo y sus 
impactos en las Ciudades Patrimonio de la Humanidad: estudios comparados entre México y España (TROITIÑo, M.Á; CALLE, M. DE LA; RUIZ, A; HIRIART, C.A. coords.). Guanajuato, Universidad de Guanajuato, Libros a Cielo Abierto, 146-162.

TURESPAÑA (2001): Turismo Cultural. Serie: Estudios de Productos Turísticos. Madrid, Instituto de Turismo de España - TURESPAÑA.

ViÑAYO GONZÁLEZ, A. (2007): Real Colegiata de San Isidoro de León. Al filo de medio siglo de restauraciones y renovaciones (1956-2003). León, Editorial Isidoriana.

WORLD TOURISM ORGANISATION - ICOMOS (1993): Tourism at World Heritage Cultural Sites. The Site Manager's Handbook. Madrid.

WORLD TOURISM ORGANISATION (2005): Handbook Tourism Congestion Management at Natural and Cultural Sites. Madrid. 